\title{
Creativity and tolerance for uncertainty predict the engagement of emotional intelligence in personal decision making
}

\author{
Elizaveta M. Pavlova, Tatyana V. Kornilova
}

Lomonosov Moscow State University, Moscow, Russia

\begin{abstract}
The current study investigated the relationships among creativity, tolerance for uncertainty (TU), and emotional intelligence (EI) in a selected sample of undergraduate students $(n=145)$. We found differential patterns of intercorrelations among these constructs in students majoring in psychology, music, and stage directing, and we also established group differences in these constructs in the three groups of students. Thus, the use of emotional information in personal decision making in different subsamples is assumed to be achieved through hierarchies of diverse processes. Overall, creativity, EI, and TU acted as predictors of the use of emotional information in decision making.
\end{abstract}

Keywords: personal choice, creativity, emotional intelligence, tolerance for uncertainty, creative professions

Psychological regulation of choice is closely related to the processes involved in overcoming uncertainty via determination of goals, choice criteria, personal values, and so forth. Choice is frequently described as an act that is not determined but rather one that involves the online development of regulation processes while choices are being made. These emergent regulation systems, in turn, utilize and realize both intellectual and personal abilities available to the subject.

We previously showed that multiple components are actively involved in the personal choice and decision-making processes. Specifically, we focused on motivation (the least conscious level of regulation), implicit theories (partly conscious components), risk preparedness and rationality traits, intuitive style, reflectiveness, self-efficacy, and self-esteem (as a component of self-consciousness) (see Kornilova, Chumakova, Kornilov, \& Novikova, 2010, for a review).

Evidence also points to the important roles played by psychometric intelligence and tolerance for uncertainty in the context of psychological choice (Kornilova \& Novikova, 2011). Although intelligence has been studied as a higher-order latent trait for decades, the latent-trait status of the tolerance for uncertainty has been demonstrated only recently (Kornilova, 2010b). The conceptualization of choice as being underspecified by external conditions or preexisting knowledge bases and 
biases and thus requiring the formation of certain "novelties" (or new formations) in the process is best captured by the notion of productive solutions.

In a series of experimental studies, Kornilova and her team showed that static snapshots of the overall patterns of the relationships among various predictors of choice (viewed as a dispositional characteristic) might not be sufficient to explain the integral regulation of choice under uncertainty. They found that individual differences in the personal regulation of choice are better explained via the inclusion of dynamic regulative systems (DRSes) that form in the process of functional development. In addition, various levels of procedural regulation included in DRSes work jointly rather than independently. One of the key assumptions of the DRS approach is that it is difficult to determine the leading level of regulation and the specific characteristics of the regulatory hierarchy of processes for a given person in a given (uncertain) situation.

In this study, we examined the regulating role of emotional intelligence (EI) as a constellation of processes involved in DRSes. This research is grounded in the idea of the unity of intelligence and affect developed by L.S. Vygotsky, A.R. Luria, and O.K. Tikhomirov. We believe that the application of the DRS framework to studying EI offers a new perspective on the old problem of the unity of intelligence and affect.

Historically, several approaches to understanding the relationship between human thought and emotion were proposed. Vygotsky (1999) argued that every human idea contains the relationship of a given individual to the reality around him or her, and this approach was further developed in Vygotsky's work on (levels of) transitions to the field of meaning in the process of thought formation (as generated by the motivational sphere of consciousness). Using a wealth of experimental material, the Tikhomirov school has demonstrated that emotion precedes actual decision making in the temporal structure of cognitive processing (Tikhomirov, 1984). Such emotional anticipation not only precedes verbally-mediated choice but also changes the orientation of intellectual strategies. Crucially, Tikhomirov's approach distinguishes between more and less creative cognitive processes depending on the extent to which novelties are expressed in them. Such novelties represent the productive components of decision making and may appear both "on the side" of the subject as well as "on the side" of the object (e.g., in the shape of new motives or meanings). However, Rubinshtein (2000) argued that psychologists should focus on the "unity of the emotional (or affective) and the intellectual within both emotion and intelligence" (p. 562). Thus, although Russian psychologists focus on studying regulatory functions of emotions in cognitive processing and thinking, we would like to argue that new lines of research on the topic might be especially productive if they capitalized on recent interdisciplinary conceptual developments, such as the notion of emotional intelligence (EI).

The notion of EI is closely related to the concept of social intelligence, which originated in Edward Thorndike's seminal work on human intelligence and has been subsequently developed by a variety of researchers in the fields of human abilities and personality. Although there is no universally accepted definition of EI, EI can be viewed both as a special variety of cognitive ability and as a personality trait (Mayer, Salovey, \& Caruso, 2000). The concept of EI was used in a number of models that generally separated perceiving, identifying, understanding, express- 
ing, and using emotions to regulate behavior into different facets of EI (e.g., Mayer, DiPaolo, \& Salovey, 1990; Roberts, Matthews, Zeidner, \& Lucin, 2004). Thus, the idea of EI as a person's capacity to "work" with emotional information captures its unique focus on the social aspects of human functioning rather than on "cold" problem solving.

We would like to argue that EI should be viewed as one of the crucial processes involved in DRSes given its importance for decision making in both real-life environments and everyday activities. To a large extent, decision making and choice can be mediated by the use of emotional information in order to facilitate such processes as acceptance of uncertainty and overcoming uncertainty. However, little is known about the relationship between EI and such characteristics as tolerance for uncertainty (TU), a trait that reflects the degree to which one's functioning in novel, uncertain, and ambiguous environments is successful. TU as an index of successful regulation under uncertainty, however, has been previously linked to creativity (Kornilova, 2010b; Kornilova et al., 2010; Lubart, Mushiru, Torgman, \& Zenasni, 2009). Thus, we previously showed that tolerance for uncertainty was a positive predictor of creativity over and above the contribution of intelligence and that a similar, but opposite in direction, effect obtained for intolerance for uncertainty (Kornilova \& Kornilov, 2010).

Studies on the relationship between creativity and emotions typically focus on the emotional facilitation of creative processes, but there is a definite lack of evidence with respect to the link between creativity and EI itself. A few studies produced inconclusive results; they linked EI to creative personality rather than to creative ability (measured as divergent thinking) (Guastello, Guastello, \& Hanson, 2004; Sanchez-Ruiz, Hernandez-Torrano, Perez-Gonzalez, Batey, \& Petrides, 2011).

An interesting attempt to relate the domains of emotions and creativity was made by Averill (2000) in his work on "emotional creativity" as a specific capacity to create novel emotional experiences. In this approach, creative behavior is achieved through the process of the construction and development of emotional experiences and responses. Averill's approach supports the hypothesized link between EI and creativity because the processing of emotional information and creative thinking include intuitive processes, which, in turn, are related to insight.

The goal of the study reported here was to identify the relationships among TU, EI, and creativity in subsamples of students with different majors (henceforth, professions). Specifically, we studied students of professions that are characterized by varying creative demands and varying EI demands. According to Klimov's classification of professions, ${ }^{*}$ the sources of emotions are mostly related to the orientation toward others vs. orientation toward the emotional aspects of (or contributions to) artistic activity in the "person-person" vs. the "person-art image" professions. From this point of view, psychology students and student (stage) directors, for example,

* Russian psychologist E.A. Klimov divided all professions into five types: technology, nature, sign systems, art imagery, and other people. Professions of the "person-person" type involve constantly working with people and communicating with them in the course of professional activities. Professions of the "person-art imagery" type belong directly in the realm of the arts. 
can be placed in the categories of low- vs. high-creativity professions. Psychology presumes a greater degree of orientation toward others and, at the same time, a sufficient amount of uncertainty and the use of emotional information.

Thus, our use of different professional groups exemplifies the quasi-experimental approach and makes it possible to distinguish the varying regulative roles of EI in individuals with different professional requirements for the use of emotional information. Specifically, we compared the following three professional groups: psychologists (representing the "person-person" type of profession), stage directors (representing a creative profession that belongs to the "person-person" type), and musicians (representing a creative profession that belongs to the "person-art image" type). The participants in this study were not accomplished professionals but rather students with a relevant educational background (i.e., they were mastering one of the three professions).

A study that compared members of different professions using the Russian MSCEIT adaptation sample (Sergienko \& Vetrova, 2010) found that representatives of the creative professions (painters and musicians) and the noncreative professions (managers) differed on EI. It was also determined that these differences were attributable mostly to gender differences. However, another study failed to find gender differences in EI on a self-report measure of the construct (Lyusin \& Ushakov, 2009).

We have shown previously that the processes of acceptance of uncertainty are included in the functional development of new formations, in conjunction with intellectual potential (Kornilova, 2010b; Kornilova et al., 2010). To the best of our knowledge, there has been no systematic research to determine which of the traits discussed above (TU, EI, creativity) reach the highest levels in DRSes when decisions are made in situations that do or do not require using emotional information.

Although the relationship between creativity and TU is frequently mentioned in theoretical discussions about the nature of creativity and the processes that support it, it has rarely been investigated empirically. The only published studies available to us at the time of writing were the studies done by Kornilova and Kornilov (2010), Tengano (1990), and Zenasni, Besancon, and Lubart (2008). In sum, even though all these studies demonstrated that TU supports creativity, they used different measures and produced somewhat different results (e.g., with respect to the relationship of TU and performance-based and personality-related measures of creativity). We believe that this question warrants further investigation and necessitates replication studies.

We argue that it is not sufficient to simply postulate that creative potential, TU, and EI are mutually interrelated. It is also necessary to identify the specific systems of such interrelations (in hypothetical DRSes) that are characterized, in part, by belonging to a specific professional group. Such DRSes are formed through mastering professional skills and might reflect psychological criteria for self-selection (of the various professions). Verification of the hypotheses concerning DRSes would facilitate determining how the above-mentioned factors regulate the use of emotional information.

The current study investigated one general hypothesis-namely, that EI (reflected in the observed indicators of interpersonal and intrapersonal emotional 
intelligence) is a prerequisite for choice and decision making under uncertainty mediated by the use of emotional information. The hypotheses investigated in the study were:

$\mathrm{H}_{1}$. EI is positively related to TU given their simultaneous, fundamental involvement in interpersonal interactions.

$\mathrm{H}_{2}$. In decision making, individuals with higher EI more frequently prefer the alternatives that involve orienting toward emotions (one's own and those of other people).

$\mathrm{H}_{3}$. In addition to EI, TU and creativity also predict various characteristics of decision making.

\section{Method}

\section{Participants}

One hundred and forty-five undergraduate students $(60.4 \%$ female, age $M d n=$ $19.00, S D=3.43)$ from three universities participated in this study. The first sample consisted of 88 psychology majors from Lomonosov Moscow State University (72.7\% female, age $M d n=19.00, S D=1.06)$. The second sample consisted of $27 \mathrm{stu}-$ dents from the Moscow Conservatory (48.2\% female, age $\mathrm{Med}=22.00, S D=2.78$ ). The third sample consisted of 8 students from the All-Russian State University of Cinematography and 22 students from the Russian University of Dramatic Art, majoring in stage directing ( $33 \%$ female, age $M d n=25.50, S D=5.52)$.

\section{Measures}

Personal choice involving EI

We designed a set of verbal tasks to assess the propensity to use or avoid using emotional information in different situations (communicating with a close friend, a boss, or an acquaintance, or in the process of self-understanding). The tasks involved different models of interactional situations, and alternatives were constructed to imply either using or ignoring emotional information (see Appendix 1).

\section{Verbal creativity}

Verbal creativity was assessed using two different measures: (1) the Creative Stories task, which is part of a comprehensive assessment of intelligence developed by Kornilov and Grigorenko (2010), and (2) our modification of Sternberg's Cartoon Task (Sternberg, 2006; Pavlova \& Kornilova, 2012). For the Creative Stories task, participants were asked to write a short story based on one of five unusual titles. For the Cartoon Task, participants were asked to create titles for six different cartoons. Three and four experts, respectively, assessed the subjects' responses on the tests, using criteria formulated and scoring rubrics originally developed by Sternberg (originality, complexity, emotionality, and descriptiveness or task appropriateness for the Creative Stories; originality, cleverness, humor, and task appropriateness for the Cartoon Task). Final creativity scores were calculated using the multifaceted Rasch modeling approach. 


\section{Tolerance for uncertainty}

Tolerance/intolerance for uncertainty was assessed using the New Questionnaire of Tolerance for Uncertainty (Kornilova, 2010a). This questionnaire consists of three subscales: tolerance for uncertainty (TU) as an ability to function in uncertain situations, intolerance for uncertainty (ITU) as a tendency to avoid uncertainty in the "world of ideas," and interpersonal intolerance for uncertainty (interpersonal ITU) as a tendency to seek certainty in interpersonal communication.

\section{Emotional intelligence}

EI was assessed using Lyusin's EI questionnaire (Lyusin \& Ushakov, 2004), a selfreport measure that contains six subscales-perception of emotions, identification of emotions, and control of emotions (each with respect to interpersonal and intrapersonal domains) - as well as two summary scales of interpersonal and intrapersonal EI. For our study, we used only the summative interpersonal and intrapersonal EI scores.

\section{Results}

\section{Significant differences among subsamples}

We found significant group differences with respect to interpersonal ITU $(p<.002)$, with the stage-director students demonstrating lower levels of ITU compared with both the psychology and music students.

We also found significant group differences among subsamples on the Cartoon Task creativity measure. The psychology students demonstrated lower creativity compared with the music students $(p<.02)$, and the stage-director students displayed levels of creativity between the other two groups.

\section{Correlation analysis}

The results of the correlation analysis are presented in Table 1.

Significant correlations for the overall sample were found for the relationships between TU and interpersonal EI; interpersonal EI positively correlated with TU and ITU. Also, correlations were found on scales of the New Questionnaire of Tolerance for Uncertainty.

For the psychology students, significant correlations were found between interpersonal EI and TU and ITU; the same connection was observed for interpersonal EI and intrapersonal EI. However, our study did not reveal any correlation of measured traits with creativity within this subsample.

Correlation analysis produced somewhat different results for the subsamples of creative professionals. The music students demonstrated a correlation between ITU and interpersonal ITU. Within the group of stage-director students, interpersonal EI tended to be negatively correlated with interpersonal ITU $(\rho=-.39, p=$ $.058)$, and TU tended to be correlated with ITU ( $\rho=.37, p=.05$ ). Thus, the more emotionally competent subjects from this group were also the ones who sought less certainty in interpersonal interaction. For this group, both the striving for novelty and the acceptance of uncertainty were linked to certainty seeking, which wasn't evident for the other subsamples. 


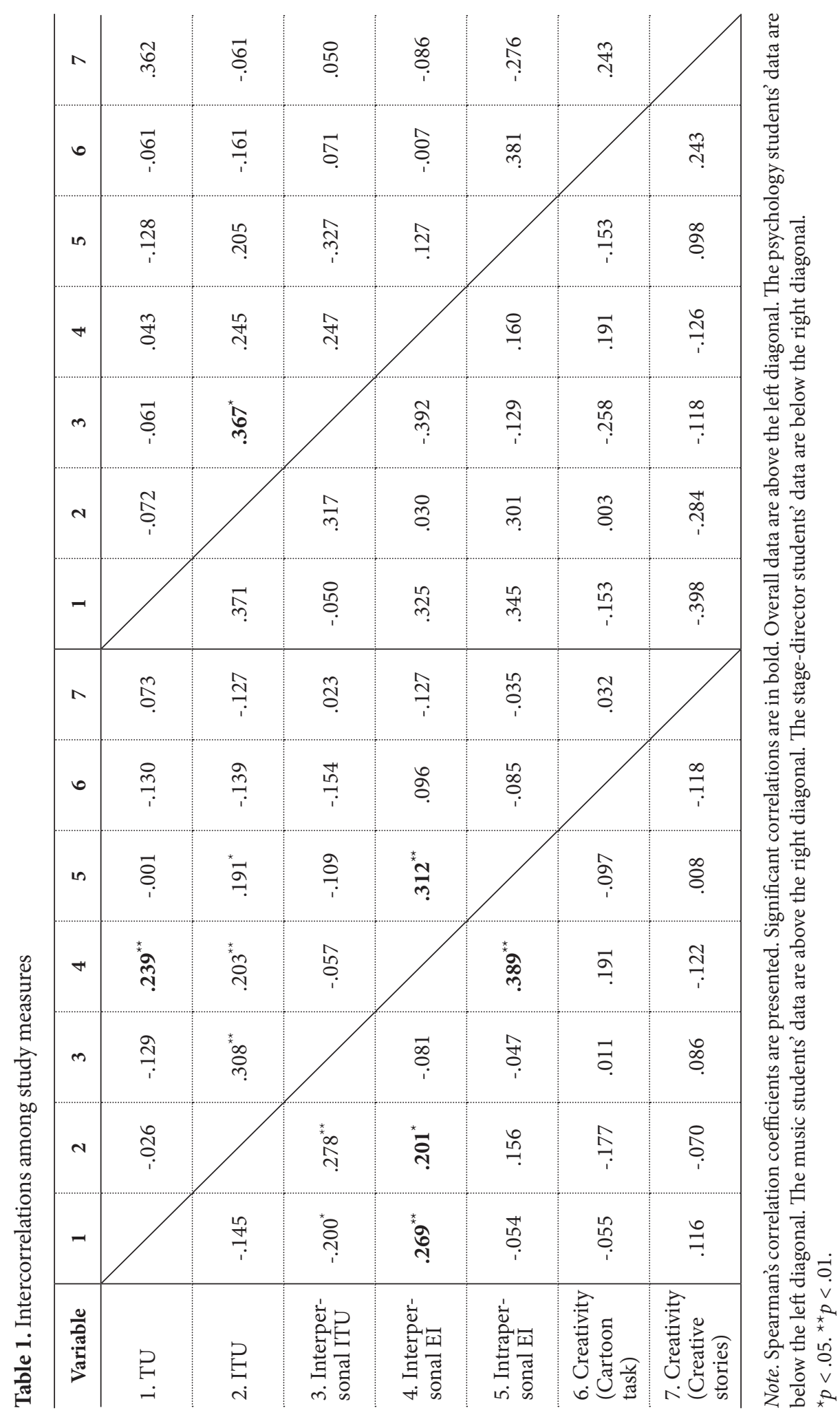




\section{Predictors of choosing to use emotional information in verbal tasks}

Significant predictors of choosing to use emotional information in verbal tasks are shown in Table 2.

Table 2. Significant predictors of choosing to use emotional information in verbal tasks

\begin{tabular}{|c|c|c|c|c|}
\hline & Overall sample & $\begin{array}{l}\text { Psychology } \\
\text { students }\end{array}$ & Music students & $\begin{array}{c}\text { Stage-director } \\
\text { students }\end{array}$ \\
\hline $\begin{array}{l}\text { Verbal task } 1 \\
\text { (communica- } \\
\text { tion with a } \\
\text { close friend) }\end{array}$ & & $\begin{array}{l}\text { Interpersonal ITU: } \\
\mathrm{B}=-.039 \\
\text { Wald }=5.121 \\
p=.024\end{array}$ & $\begin{array}{l}\text { Creative Stories: } \\
\mathrm{B}=2.040 \\
\text { Wald }=2.909 \\
p=.088\end{array}$ & \\
\hline $\begin{array}{l}\text { Verbal task } 2 \\
\text { (communica- } \\
\text { tion with an } \\
\text { acquaintance) }\end{array}$ & $\begin{array}{l}\text { TU: } \\
\mathrm{B}=.024 \\
\text { Wald }=13.194 \\
p<.001\end{array}$ & $\begin{array}{l}\text { Interpersonal EI: } \\
\mathrm{B}=.037 \\
\text { Wald }=5.258 \\
p=.022\end{array}$ & & $\begin{array}{l}\text { ITU: } \\
\mathrm{B}=.069 \\
\text { Wald }=3.434 \\
p=.064\end{array}$ \\
\hline $\begin{array}{l}\text { Verbal task } 3 \\
\text { (communica- } \\
\text { tion with a } \\
\text { boss) }\end{array}$ & $\begin{array}{l}\text { Intrapersonal EI: } \\
\mathrm{B}=.020 \\
\text { Wald }=5.602 \\
p=.018\end{array}$ & & & \\
\hline $\begin{array}{l}\text { Verbal task } 4 \\
\text { (understan- } \\
\text { ding oneself) }\end{array}$ & $\begin{array}{l}\text { Intrapersonal EI: } \\
\mathrm{B}=.054 \\
\text { Wald }=17.030 \\
p<.001\end{array}$ & $\begin{array}{l}\text { Interpersonal EI: } \\
\mathrm{B}=.059 \\
\text { Wald }=7.197 \\
p=.007\end{array}$ & $\begin{array}{l}\text { Intrapersonal EI: } \\
\mathrm{B}=.035 \\
\text { Wald }=3.375 \\
p=.066\end{array}$ & \\
\hline
\end{tabular}

The logistic regression analysis performed for the overall sample (the dependent variable was coded as 0 for the alternative that involved ignoring emotional information and 1 for the alternative that involved using emotional information) revealed that intrapersonal EI and TU predicted the choice parameters. For the subsample of psychology students, predictors in situations that involved the possibility of using or ignoring emotional information were interpersonal EI and interpersonal ITU. For the subsample of music students, we found that the significant predictors were intrapersonal EI and verbal creativity (measured by Creative Stories). In the subsample of stage-director students, ITU was the significant predictor.

In sum, we found that higher TU, creativity, and interpersonal EI characterized subjects who showed a propensity to use emotional information in decision making. For the psychology students, using emotional information was negatively related to interpersonal ITU.

\section{Discussion}

In the first part of this study we found that the three subsamples did not display significant group differences in EI. This result is consistent with results that have been published about other EI measures (e.g., Sergienko \& Vetrova, 2010). At the same time we found significant group differences in interpersonal ITU and creativity as measured by the Cartoon Task, with the stage-director students displaying the lowest levels of the desire for certainty in interpersonal relationships among the three subgroups. The stage-director students were also characterized by an average 
level of creativity. Although the psychology and music students did not differ with respect to their desire for certainty in contacts with others, the music students' creativity turned out to be significantly higher than that of the psychology students.

The results provide some evidence that the young stage directors preferred to use emotional information if they wished to avoid uncertainty in interactions with the world around them. An ability to accept uncertainty in interpersonal relations is of greater importance for stage directors than for musicians or psychologists; an essential part of stage directing is creating a product through dealings with other people, whereas for musicians creativity plays a greater regulatory role and is not linked to interpersonal interactions.

In the second part of the study we established the expected positive correlation between TU and EI. This result is consistent with the results reported by Kornilova and Novotockaya-Vlasova (2009) and thus supports our first hypothesis. Of note is that this relationship was observed specifically for the traits that did not show significant differences among the three groups.

Although belonging to a particular professional group did not seemingly influence these traits, they were in different patterns of relationships with other processes (those involved in the personal regulation of choice in situations that require using emotional information) across the three groups. This observation is supported by group differences in systems of significant predictors of choice characteristics: for the stage directors, ITU was a significant predictor, whereas for the musicians it was creativity and intrapersonal EI. Correspondingly, using emotional information or ignoring it depends on combinations of different processes and traits rather than on high levels of a single one.

The group differences in creativity that we established using the Cartoon Task might be related to specific features of the task itself: while the Creative Stories likely tap into "pure" verbal creativity, the stimuli in the Cartoon Task require flexibility in establishing relationships between words and images, an ability that characterized the musicians in our study to a larger extent than it characterized the other two groups. However, given the small sample size (and low power) we remain cautious regarding the patterns of established (and absent) group differences in creativity in our study.

We also found that traits other than EI contributed to the regulation of decision making in uncertain situations that involve communicating with other people. The relationships among these traits differed among the subsamples.

We obtained support for the second hypotheses of our study by showing that higher EI was related to a preference for alternatives that involve using emotional information in decision making. However, different facets of EI and different traits were found to be predictive of this preference in different subsamples. For the psychology students, interpersonal EI predicted choice characteristics, whereas for the music students intrapersonal EI was a more salient predictor. Although neither EI variable predicted choice characteristics in the stage directors, we found that ITU was related to these characteristics instead (i.e., the use of emotional information by the stage directors was positively related to ITU and certainty seeking). We obtained support for our third hypothesis by demonstrating that choice in uncertain situations that require using emotional information is related not only to EI but to other traits as well (TU/ITU and creativity). Our study showed that emotional 
intelligence and creativity were related to uncertainty acceptance; at the same time, EI was positively related to seeking certainty in the "world of ideas."

Given the established patterns of interrelationships among TU, EI, and creativity, we suggest viewing them as belonging to the same regulation system. We previously proposed that DRSes act as mediating factors in the psychological regulation of creative decisions and personal choice (Kornilova et al., 2010). We would like to now link this line of reasoning with the observed interrelations among the mentioned traits and argue that they are dynamically interrelated in regulating choice in verbal situations that require using emotional information or ignoring it. These interrelations differ in the developing DRSes among students engaged in mastering different professions.

Our study adds to the existing literature by demonstrating the complex patterns of the relationships among EI, TU, and creativity. Previous research showed that EI was related to creative personality but not to divergent thinking (Guastello et al., 2004; Sanchez-Ruiz et al., 2011). In addition, Zenasni and Lubart (2009) used measures of divergent thinking about emotional information and showed that EI was negatively related to creativity.

We showed that for the psychologists (representatives of a profession that involves the active use of processes of accepting uncertainty and that requires high levels of both EI and TU), creativity was independent of EI and TU. However, we found that among this group higher interpersonal EI was related to the willingness to accept a changing world and to exist in uncertain situations, while at the same time trying to bring certainty into such situations.

For the stage directors (as representatives of a creative profession that is also characterized by high demands for emotional competence), we also did not observe the involvement of creativity in the system of variables in the study. Those who were better at handling emotional information about other people were less likely to introduce certainty into uncertain situations related to interpersonal interactions.

In representatives of the "person-art image" type of profession (in this case, the musicians) creativity was included in decision making and choice DRSes, whereas for the psychologists and stage directors (members of the "person-person" types of professions), these DRSes included other traits.

Not only higher EI (in the psychologists and musicians) but also greater striving for certainty (ITU in the stage directors) can be considered a significant predictor of using emotional information in decision making. Our study demonstrated that the psychologists with higher interpersonal ITU strove to use emotional information, while the stage directors relied more on ITU in making decisions under uncertainty. The two types of intolerance (ITU and interpersonal ITU) have a differential impact on the tendency to use or to ignore emotional information among members of both creative and noncreative professions. This conclusion also supports the argument that different processes reach the highest levels of regulation in DRSes as they are formed in the course of mastering different professions. Thus, the members of creative professions of the "person-person" type (the future stage directors) used emotional information while pursuing the goal of bringing certainty to uncertain situations, whereas the psychologists, who strove for increased certainty, showed lower interest in using emotional information. 
Taken together, the results suggest that the psychology students have an integrated system of traits related to the personal regulation of choice. Some of the traits that appeared as predictors for preferring alternatives in uncertain situations involving communication or understanding oneself significantly correlated with each other, indicating that they are integrated to a greater degree in a single DRS in the psychology students than in the other subgroups in the study.

The idea of openness in such integrated systems as DRSes, taken together with the results of this study, also supports the view that EI should not be considered a strictly cognitive trait but should rather be understood as a component involved in various relationships between cognitive and personality traits in DRSes.

Finally, we previously showed that TU is positively related to creativity, while ITU has a negative impact on it (Kornilova, 2010b; Kornilova \& Kornilov, 2010). This study also demonstrated a relationship between creativity and preferences for certain alternatives in decision making that involve interpersonal relationships. Thus, creativity was at the highest levels of DRSes predicting personal choice (in uncertain situations that involve using emotional information) in members of a creative profession.

\section{Conclusions}

1. The subgroups in the study differed with respect to their creativity and interpersonal TU but not with respect to EI or TU/ITU.

2. TU was related to EI.

3. In the general sample, higher creativity, EI, and TU were predictive of using emotional information in making decisions in uncertain situations that involve communication.

4. Various predictors for preferring alternatives were related to using or ignoring emotional information in decision making under uncertainty, specifically: interpersonal ITU and interpersonal EI for the psychology students; ITU for the stage-director students (the relationship was in the opposite direction); creativity and intrapersonal EI for the music students.

\section{Acknowledgment}

The article was written with financial support from RGNF, project № 13-0600049 .

\section{References}

Averill, J. R. (2000). Intelligence, emotion, and creativity. From trichotomy to triunity. In R. Bar-On \& J.D.A. Parker (Eds.), Handbook of emotional intelligence: Theory, development, assessment, and application at home, school, and in the workplace (pp. 277-298). San Francisco: Jossey-Bass.

Guastello, S. J., Guastello, D. D., \& Hanson, C. A. (2004). Creativity, mood disorders, and emotional intelligence. Journal of Creative Behavior, 38, 260-281. doi: 10.1002/j.2162-6057.2004. tb01244.x 
Kornilov, S. A., \& Grigorenko, E. L. (2010). Metodichesky kompleks dlya dianostiki akademicheskih, tvorcheskih i prakticheskih sposobnostey [An assessment battery for analytical, creative, and practical abilities]. Psikhologicheskiy Zhurnal [Psychological Journal], 31(2), 90-103.

Kornilova, T. V. (2010a). Noviy oprosnik tolerantnosti k neopredelennosti [The New Questionnaire of Tolerance for Uncertainty]. Psikhologicheskiy Zhurnal [Psychological Journal], 31(1), $74-86$

Kornilova, T. V. (2010b). Tolerantnost k neopredelennosti i intellect kak predposilki kreativnosti [Tolerance for uncertainty and intelligence as predictors of creativity]. Voprosi Psihologii [Issues in Psychology], 5, 3-12.

Kornilova, T. V., Chumakova, M. A., Kornilov, S. A., \& Novikova, M. A. (2010). Psihologiya neopredelennosti: Edinstvo intellectialnolichnostnogo potenciala cheloveka [The psychology of uncertainty: The unity of the intellectual-personal potential of a person]. Moscow: Smysl.

Kornilova, T. V., \& Kornilov, S. A. (2010). Intelligence and tolerance / intolerance for uncertainty as predictors of creativity. Psychology in Russia: State of the Art, 3, 240-255. doi: 10.11621/ pir.2010.0012.

Kornilova, T. V., \& Novikova, M. A. (2011). Samoocenka v structure lichnostnogo potenciala cheloveka [Self-esteem in the structure of the intellectual-personal potential of a person]. Psikhologicheskiy Zhurnal [Psychological Journal], 32(2), 25-35.

Kornilova, T. V., \& Novotockaya-Vlasova, E. V. (2009). Sootnoshenie nravstvennogo samosoznaniya lichnosti, emocionalnogo intellecta i prinyatiya neopredelennosti [The relationship of the moral self-consciousness of a person, emotional intelligence, and the acceptance of uncertainty]. Voprosi Psihologii [Issues in Psychology], 6, 61-70.

Lubart, T., Mushiru, H., Torgman, S., \& Zenasni, F. (2009). Psihologiya kreativnosti [The psychology of creativity]. Moscow: Cogito-Centr.

Lyusin, D. V., \& Ushakov, D. V. (Eds.). (2004). Social intelligence theory, measures and applications. Moscow: Institute of Psychology, Russian Academy of Sciences Publ.

Lyusin, D. V., \& Ushakov, D. V. (Eds.). (2009). Socialniy i emocionalniy intellect: Ot processov $k$ izmereniyam [Social and emotional intelligence: From processes to measures]. Moscow: Institute of Psychology, Russian Academy of Sciences Publ.

Mayer, J. D., DiPaolo, M. T., \& Salovey, P. (1990). Perceiving affective content in ambiguous visual stimuli: A component of emotional intelligence. Journal of Personality Assessment, 54, 772-781. doi: 10.1207/s15327752jpa5403\&4_29

Mayer, J. D., Salovey, P., \& Caruso, D. R. (2000). Emotional intelligence as zeitgeist, as personality, and as a mental ability. In R. Bar-On and J.D.A. Parker (Eds.), The handbook of emotional intelligence: Theory, development, assessment, and application at home, school, and in the workplace (pp. 92-117). San Francisco: Jossey-Bass.

Pavlova, E. M., \& Kornilova, T. V. (2012). Kreativnost i tolerantnost k neopredelennosti kak predictori aktualizacii emocionalnogo intellecta $\mathrm{v}$ lichnostnom vibore [Creativity and uncertainty avoidance as predictors of the actualization of emotional intelligence in personal choice]. Psihologichesky Zhurnal [Psychological Journal], 33(5), 39-49.

Roberts, R. D., Matthews, G., Zeidner, M., \& Lucin, D. (2004). Emocionalniy intellect: Problemi, teorii, izmereniya i primeneniya na praktike [Emotional intelligence: Problems, theories, assessment, and practical application]. Psihologiya. Zhurnal Visshei Shkoli Economiki [Psychological Journal of the Higher School for Economy], 1(4), 3-26.

Rubinshtein, S. L. (2000). Osnovi obshei psihologii [Foundations of general psychology]. St. Petersburg: Piter. 
Sanchez-Ruiz, M. J., Hernandez-Torrano, D., Perez-Gonzalez, J. C., Batey M., \& Petrides, K. V. (2011). The relationship between trait emotional intelligence and creativity across subject domains. Motivation \& Emotion, 35(4), 461-473. doi: 10.1007/s11031-011-9227-8

Sergienko, E. A., \& Vetrova, I. I. (2010). Test J. Mayera, P. Soloveya, D. Caruso "Emocionalniy Intellect" (MSCEIT v. 2.0): Rukovodstvo [The Mayer-Solovey-Caruso Emotional Intelligence Test (MSCEIT 2.0): Manual]. Moscow: Institute of Psychology, Russian Academy of Sciences Publ.

Sternberg, R. J., \& the Rainbow Project Collaborators. (2006). The Rainbow Project: Enhancing the SAT through assessments of analytical, practical, and creative skills. Intelligence, 34, 321-350. doi: 10.1016/j.intell.2006.01.002

Tengano, D. W. (1990). Relationship of tolerance of ambiguity and playfulness to creativity. Psychological Reports, 66, 1047-1056. doi: 10.2466/pr0.1990.66.3.1047

Tikhomirov, O. K. (1984). Psihologiya mishleniya [The psychology of thinking]. Moscow University Press.

Vygotsky, L. S. (1999). Mishlenie i rech [Reasoning and speech] (5th ed.). Moscow: Labirint.

Zenasni, F., Besancon, M., \& Lubart, T. (2008). Creativity and tolerance of ambiguity: An empirical study. Journal of Creative Behavior, 42(1), 61-73. doi: 10.1002/j.2162-6057.2008. tb01080.x

Zenasni, F., \& Lubart, T. (2009). Perception of emotion, alexithymia and creative potential. Personality and Individual Differences, 46(3), 353-358. doi: 10.1016/j.paid.2008.10.030

\section{Appendix 1}

\section{Example of a Verbal Task}

You meet your close friend and notice that he is upset about something, but when you ask him what happened he doesn't tell you; instead he replies that "everything's fine." When this person acts in this way, it is very difficult for you to talk to him. What would you do?

(a) You wouldn't try to find out the reason by asking this person directly. Instead, you would ask your common friends about what happened and whether you can help.

(b) You would understand that he probably needs your help, but you wouldn't ask persistently because he doesn't want to talk.

(c) You would forget about it quickly because you have a lot of your own problems.

(d) You would start talking about something else and lead the conversation to a point where your friend could tell you everything.

(e) You would find out what's going on using some other method, such as

(fill in the blank).

Received: 05 October 2013

Accepted: 01 November 2013

Available online: 15 December 2013 